\title{
Autophagy Related Gene (ATG3) is a Key Regulator for Cell Growth, Development, and Virulence of Fusarium oxysporum
}

\author{
A. Rehman Khalid ${ }^{1}$, Xiulan Lv ${ }^{1}$, Muhammad Naeem ${ }^{2}$, Khalid Mehmood ${ }^{3}$, Hamayun Shaheen ${ }^{4}$, \\ Pan Dong ${ }^{1}$, Dan Qiu ${ }^{1}$ and Maozhi Ren ${ }^{1, *}$ \\ 1 School of Life Sciences, Chongqing University, Chongqing 401331, China \\ Bioengineering College, Chongqing University, Chongqing 401331, China \\ Department of Botany, University of Azad Jammu \& Kashmir, Muzaffarabad 05822, Pakistan \\ 4 Department of Entomology, University of Poonch AJK, Rawalkot 12350, Pakistan \\ * Correspondence: renmaozhi@cqu.edu.cn
}

Received: 27 May 2019; Accepted: 13 August 2019; Published: 28 August 2019

check for updates

\begin{abstract}
Fusarium oxysporum is the most important pathogen of potatoes which causes post-harvest destructive losses and deteriorates the market value of potato tubers worldwide. Here, F. oxysporum was used as a host pathogen model system and it was revealed that autophagy plays a vital role as a regulator in the morphology, cellular growth, development, as well as the pathogenicity of F. oxysporum. Previous studies based upon identification of the gene responsible for encoding the autophagy pathway components from F. oxysporum have shown putative orthologs of 16 core autophagy related-ATG genes of yeast in the genome database which were autophagy-related and comprised of ubiquitin-like protein atg3. This study elucidates the molecular mechanism of the autophagy-related gene Foatg3 in F. oxysporum. A deletion $(\Delta)$ mutants of F. oxysporum (Foatg $3 \Delta)$ was generated to evaluate nuclear dynamics. As compared to wild type and Foatg3 overexpression (OE) strains, Foatg3 $\Delta$ strains failed to show positive MDC (monodansylcadaverine) staining which revealed that Foatg 3 is compulsory for autophagy in F. oxysporum. A significant reduction in conidiation and hyphal growth was shown by the Foatg $3 \Delta$ strains resulting in loss of virulence on potato tubers. The hyphae of Foatg $3 \Delta$ mutants contained two or more nuclei within one hyphal compartment while wild type hyphae were composed of uninucleate hyphal compartments. Our findings reveal that the vital significance of Foatg3 as a key target in controlling the dry rot disease in root crops and potato tubers at the postharvest stage has immense potential of disease control and yield enhancement.
\end{abstract}

Keywords: Fusarium oxysporum; ATG3 gene; autophagy; potato dry rot; disease control

\section{Introduction}

Fusarium oxysporum is one of the most important fungal pathogens of tubers and root crops responsible for crop failure and yield losses across the globe [1]. The fungus attacks the crops at multiple stages initially causing the Fusarium wilt at planting stage followed later by the dry rot at storage stage, decreasing the crop nutrition value and causing huge market losses [2]. The yield losses were estimated between $6 \%$ to $25 \%$ annually in the field and $60 \%$ losses were recorded during storage conditions $[3,4]$. F oxysporum can be a seed-borne, soil-borne, and vascular colonization pathogen $[5,6]$. This fungus is ubiquitous in soil and in decaying plants material and acts as a decomposer. A study was carried out by Martius in 1842 and he found that the pathogen of potato dry rot can be a fungus, which was named a Fusisporium, and later on transformed to Fusarium oxysporum [7].

Crop tubers and roots attacked by the dry rot disease are characterized by shrinking and shriveling with lesions on the outer sides, whereas simultaneously brown to black rot damages the roots/tubers 
internally [8]. This pathogen penetrates into the tuber/root through wounds and then induces rot diseases, the infectious tissue becomes brown, dark red, and then form a streak, which rises up from ground level. With time course the oldest leaves become chlorotic and young leaves become flasks [1]. Thirteen species of Fusarium have been reported as a pathogen of dry rot [6]. From dry rotted tubers at harvest and post harvest stages, members of Fusarium species were reported as an important factor in causing disease [7]. During harvesting time, climatic conditions such as temperature, moisture level, as well as harvesting and handling methods, play a crucial role in the development of infection. Due to high temperature $\left(25-30^{\circ} \mathrm{C}\right)$ and high moisture level, tubers are most susceptible to infection as well as inefficient application of harvesting tools [9,10]. So far, for the control of F. oxysporum, chemical approaches have been used widely but the application of fungicides to control plant diseases causes adverse effects on the environment, soil, plants, and humans. The fumigants like methyl bromide and disinfectants like sodium hypochlorite can be harmful for young plants and cause risk to the handler and serious damage to the environment, and are not appropriate for the application [11]. Therefore, due to limitations associated with conventional, physical and chemical control methods, the resistance sources appears as a most promising technique to control phytopathogens.

Autophagy is a conserved cellular mechanism responsible for recycling and removal of cytoplasmic components including the organelles and proteins [12,13]. There are three pathways of autophagy which are existing in eukaryotes (macro, micro, and mediated autophagy), macro autophagy has been evaluated in plants, fungi, and animals [12]. Recently in yeast species Hansenula polymorpha, Saccharomyces cerevisiae, and Pichia pastoris, genetic analysis was performed and 42 autophagy-related (ATG) genes were reported. Among these 42 genes, 20 are involved in core autophagic machinery whereas the remaining 22 genes are involved in the execution of autophagy-related specific pathways triggered by a diverse array of physiological stimuli [14-19]. Recent evidence suggested that autophagy is an important factor in developmental processes of filamentous fungi such as secondary metabolism, cell differentiation, and pathogenicity [20,21]. In the current study, we have analyzed the role of F. oxysporum Foatg3 in vegetative growth of plant pathogenic fungi, and to evaluate the importance of autophagy during different developmental stages of F. oxysporum by generating Foatg3 deletion mutant and Foatg3 overexpression strains.

\section{Materials and Methods}

\subsection{Fungus Isloation and Culturing}

Fusarium oxysporum strains were isolated from the infected potato tubers. These isolated strains were sensitive to the HygB at concentrations $>30 \mathrm{mg} / \mathrm{mL}$ and hence were used as wild type (WT) strains in the study. The suspension of the conidia extracted from the strains was prepared by adding $50 \%$ glycerol and stored at $-80^{\circ} \mathrm{C}$. We used fresh potato dextrose agar (PDA) broth medium for mycelial and conidial growth at $25^{\circ} \mathrm{C}$ The Agrobacterium tumefaciens strain (GV3101) grown on LB media was used for the transformation of the Fusarium oxysporum conidia [22].

\subsection{Fungal Transformastion}

Agrobacterium tumefaciens-mediated transformation (ATMT) process as mentioned in the literature was performed with slight modifications. The A. tumefaciens GV3101 strains containing PPk2 vector were grown on PDA amended media at $28^{\circ} \mathrm{C}$ The culture was mixed in a condial suspension of $107 / \mathrm{mL}$ at an optical density of $660 \mathrm{~nm}(\mathrm{OD} 660)$ reached at 0.5 with equal concentration. The fungal culture was then placed into induction medium (IM) with an optical density value of OD600 $=0.15$ comprising of $200 \mathrm{mM}$ acetosyringone (AS) and it was further cultured for $6 \mathrm{~h}$ on an orbital shaker $(200 \mathrm{rpm})$ at $28^{\circ} \mathrm{C}$ and $250 \mathrm{mM}$ mixture was then taken out and kept on a nitrocellulose filters having a diameter of $80 \mathrm{~mm}$ with a $0.45 \mathrm{~mm}$ pore size (Whatman, Tokyo, Japan) on a co cultivation medium for a time period of 48 h. The cultured filters were further transferred to a HygB $(50 \mathrm{mg} / \mathrm{mL})$ and cefotoxime $(500 \mathrm{mg} / \mathrm{mL})$ amended selected medium to inhibit the A. tumefaciens growth. The randomly selected transformants 
were transferred to PDA media after 7 days, selected randomly after seven days, and then transferred onto HygB (50 mg/mL) enriched PDA media [23].

\subsection{Generation of Deletion Mutants}

The fusion polymer chain reaction PCR was used to generate deletion mutant of Foatg 3 created by replacing open reading frame (ORF) of HygB resistance cassette [24]. Three primer pairs, i.e., P1/P2, P3/P4, and P5/P6 were used to amplify fragments of Foatg3, including 1000-bp upstream and downstream fragments, along with the 1040-bp HygB resistance cassette, from vector psilent- 1 . After the fusion of the Foatg 3 fragments with U-Hph-D, the digestion was performed with the restriction enzymes AsiSI and SbfI ligated with PPk2 vector (Figure S2A). The PPk2-U-Hph-D recombinant plasmid of PPk2-U-Hph-D was transferred into the WT of F. oxysporum following the standard protocol [23]. The transformants screening was carried out by PDA media supplemented with HygB ( $50 \mu \mathrm{M}$ F2du; $50 \mathrm{mg} / \mathrm{mL}$ ). F-hph/R-hph PCR screening was used for the confirmation of the followed by quantitative polymerase chain reaction (qPCR) for the identification of the deletion mutants. In the experiment, F-hph/R-hph to $1021 \mathrm{bp}$ was used for determining that whether the HygB is a single copy of the inserted mutant. Table S1 shows the details of the qPCR primers used.

\subsection{Overexpression of FoATG3 Mutant Strains}

The $\operatorname{atg} 3 F / R$ primer was used for the amplification of the cDNA from the total RNA of Foatg3 ORF of F. oxysporum which corresponded to the 7 initial ORF codons, additional cytosine, and NotI restriction site. Atg3-12 corresponded to the last 7 ORF codons with SbfI restriction site and additional cytosine for the reverse complement. Following this, the formed band was cloned to the p8GWN vector which was the plasmid template sued for the PCR amplification. The first 8 codons of AscI and SbfI restriction sites were corresponded by the atg3-F primer. The amplified DNA fragment was cloned into the vector F303 which resulted in the FoATG3/F303 plasmid. PCR amplification was used to obtain a Foatg 3 fusion fragment $(2.8 \mathrm{~kb})$ controlled by the trpC promoter. Similarly, the PCR amplification resulted in the trpC terminator using the Foatg3R and Foatg3F primer pair (Table S1), which was further utilized for the formation of the protoplast strains (Figure S2B).

\subsection{Evaluation of Radial Growth, Conidiation, Formation, and Germination}

A PDA media containing $\mathrm{HygB}(50 \mathrm{mg} / \mathrm{mL})$ was used to analyze the radial growth and formation of the conidia. Conidia were harvested from a 10 days old culture followed by a filtration by a two layered lens paper and then re-suspension in sterile water to $1 \times 10^{7}$ spores $/ \mathrm{mL}$ concentration. The conidial suspensions of WT, Foatg $3 \Delta$, and OE strains were inoculated on plates and allowed to incubate at $25^{\circ} \mathrm{C}$ followed by a daily observation of the colony diameters and strain colors. Conidia $\left(10^{2}\right)$ were inoculated in PDB medium $(1 \mathrm{~mL})$ with continuous shaking $(150 \mathrm{rpm})$ and the germination was observed at a time span of $7 \mathrm{~h}, 12 \mathrm{~h}, 21 \mathrm{~h}, 28 \mathrm{~h}, 36 \mathrm{~h}$, and $48 \mathrm{~h}$, respectively. The rate of conidial germination was determined by using the blood counting chamber at $12 \mathrm{~h}$ [24]. The data was statistically analyzed by using SPSS v.15.0 software for WindowsR (LEAD Technologies, Inc., Charlotte, NC, USA), which used student $t$-test at $p \leq 0.05$. Fresh micro conidia $\left(5 \times 10^{7}\right)$ grown on PDA medium $\left(5 \mathrm{~mL}, 14 \mathrm{~h}, 28^{\circ} \mathrm{C}\right)$ with $170 \mathrm{rpm}$ shaking for calcoflour white (CFW) staining followed by incubation for $5 \mathrm{~min}$ in a dark room prior to the microscopic analysis $(10 \mu \mathrm{m} \mathrm{CFW})$.

\subsection{RNA Extraction}

The F. oxysporum strain was incubated in liquid PDA medium at $27^{\circ} \mathrm{C}$ in the darkness for $24 \mathrm{~h}$. After $24 \mathrm{~h}$, the hypha was collected for RNA extraction. The RNA was extracted by using RNAiso plus (Takara, Kusatsu, Japan), as detailed in manufactured protocol in $10 \mathrm{~mL}$ total sample volume $(5.0 \mu \mathrm{L}$ of $2 \times$ SYBR Premix Ex Taq, 1.0 $\mu \mathrm{L}$ of primer, $1.0 \mu \mathrm{L}$ of cDNA, and $3 \mu \mathrm{L}$ of distilled water deionized water). For reverse transcription reaction (cDNA) $1 \mu \mathrm{g}$ of RNA and M-MLV reverse transcription kit (program) were used. Three biological replicates were performed in this experiment [24]. 


\subsection{Quantitative RT-qPCR}

Quantitative Rt-qPCR reactions were performed using a two steps methods: $95^{\circ} \mathrm{C}$ for $30 \mathrm{~s}$, followed by 40 cycles of $95^{\circ} \mathrm{C}$ for $5 \mathrm{~s}$ and $60^{\circ} \mathrm{C}$ for $30 \mathrm{~s}$. The real time system CFX96 ${ }^{\mathrm{TM}}$ (Bio-Red, Hercules, CA, USA ) and Go Taq q-PCR Master Mix (Promega, Madison, WI, USA) were used for qRT-PCR analysis with specific pairs of primers as listed in Table S1 [25].

\subsection{Analysis of Autophagy}

Micro conidia $\left(2.5 \times 10^{8}\right)$ inoculated on PDA medium were grown for $15 \mathrm{~h}$ at $28^{\circ} \mathrm{C}$ to visualize the autophagy in the F. oxysporum. The strains were sifted to an SM medium without a N source after washing with sterile water in the presence of $4 \mathrm{mM}$ PMSF (P7626, Sigma-Aldrich, St. Louis, MO, USA). The mycelia were stained in the dark for $30 \mathrm{~min}$ with the fluorescent dye MDC (monodansylcadaverine) with concentration of $50 \mathrm{mM}$, (Sigma, D4008) after $1 \mathrm{~h}$ starvation followed by washing with water and observation under epifluorescence and differential interference contrast (DIC) microscopy [26].

\subsection{Pathogenicity Test}

We used uniform sized (100-120 g) healthy tubers of potato for the inoculation essay in the current study. Tubers were initially washed to remove contamination and excessive soil followed by dipping the tubers in $0.5 \%$ sodium hypochlorite solution for $10 \mathrm{~min}$ and then rinsing with distilled water in 3 changes. The tubers were than sliced into small pieces and air dried. The WT, Foatg $3 \Delta$, and Foatg3 OE mutant strains were incubated in the dark for 14 days on PDA medium followed by harvesting of sporangia and washing with pea broth. Inoculation of the WT, Foatg3 3 , and Foatg $3 \mathrm{OE}$ strains was carried out on dried slices by using a $20 \mathrm{~mL}$ drop of sporangial suspension $\left(1 \times 10^{4} / \mathrm{mL}\right)$ for each strain in triplicates. The inoculated tuber slices were placed in the dish on moist filter paper and then incubated for 7 days in the dark at $27^{\circ} \mathrm{C}$. The student's $t$-test was used to measure the size of grown strains on the potato slices. Each experiment was performed in the triplicate [27].

\subsection{Optical and Epifluorescence Microscopy}

The aliquot of the fungal cells was embedded in a solution of $1 \%$ agarose blocks and was analyzed under microscope M2 Dual Cam (Carl Zeiss MicroImaging GmbH, Göttingen, Germany) equipped with the recommended filter sets for optical and epifluorescence microscopic analysis. The UV light (340-380 nm) with the filter blocks was used for staining with CFW and MDC (G 365, FT 395, and LP 420). Evolve photometric digital camera (EM512) was used along with Axiovision v.4.8 software. The imagery was further processed by using adobe Photoshop CS3 [28].

\section{Results}

\subsection{Over Expression and Deletion of FoATG3 Mutants in F. Oxysporum}

Replacement of target genes was performed in F. oxysporum strains to analyze the role of Foatg3. Polymerase chain reaction (PCR) of insertion flanking regions was used to elucidate the hygromycin resistant (HygR) transformants (Figure S1). Transformants including Foatg $3 \Delta \# 1$, Foatg3 $\Delta \# 2$, and Foatg $\Delta \# 3$ successfully replacement the Foatg3 gene and executed the expected shift in accordance to our testable hypothesis (Figure S2). qPCR was further applied for the confirmation of these putative deletion mutants (Figure 1). Co-transformation of Foatg3 genes with different vectors successfully resulted in the over expression of Foatg3, which was confirmed by PCR analysis using specific primer pairs in PCR analysis (Table S1).

We evaluated autophagy in different strains on the nitrogen lacking medium. To achieve this target, the hyphae of these strains were stained with MDC, which is an indicator of autophagy that accumulates in vacuole in absence or presence of PMSF (phenylmethylsulfonyl fluoride), which is an inhibitor of vacuolar serine proteases [29,30]. During this study, nitrogen starved autophagy was observed, which 
was indicated by the presence of fluorescence dots in vacuoles and cytoplasm (Figure 2). The wild type WT and overexpressed OE Foatg3 mutants showed positive MDC staining compared to $\triangle$ Foatg3. Moreover, hyphae, which were stained positively with MDC, contained degradation of nuclei while no MDC staining was observed in nitrogen starved strains of the $\Delta$ Foatg3 mutant. Hence, we concluded that Foatg3 is a basic component and necessary for starvation-induced autophagy.

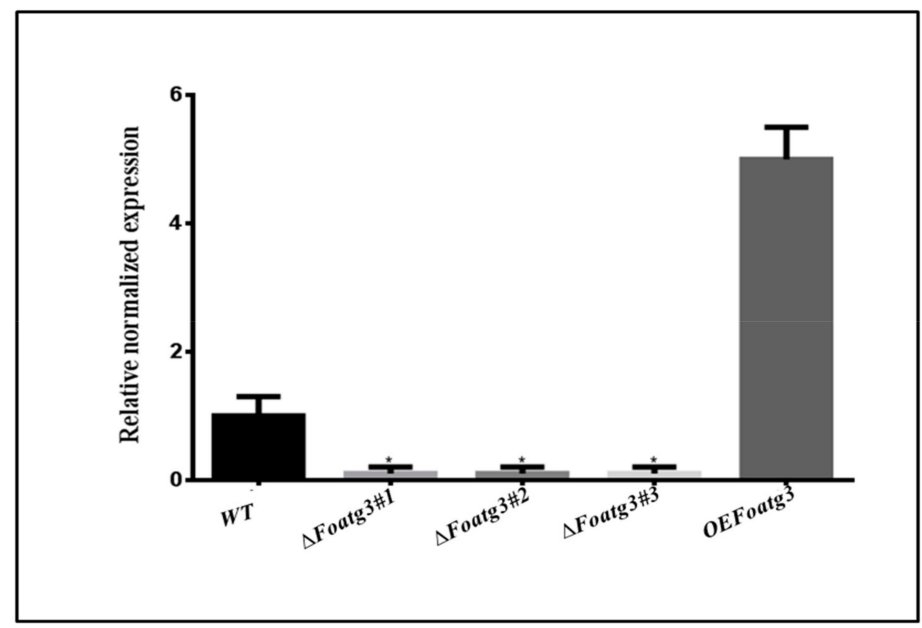

Figure 1. Verification of deletion and overexpression of mutants by quantitative polymerase chain reaction (qPCR). The error bars showing standard deviation. $t$-test with a ${ }^{*} p$ value of $<0.05$ was applied to confirm the results statistically. WT: wild type.

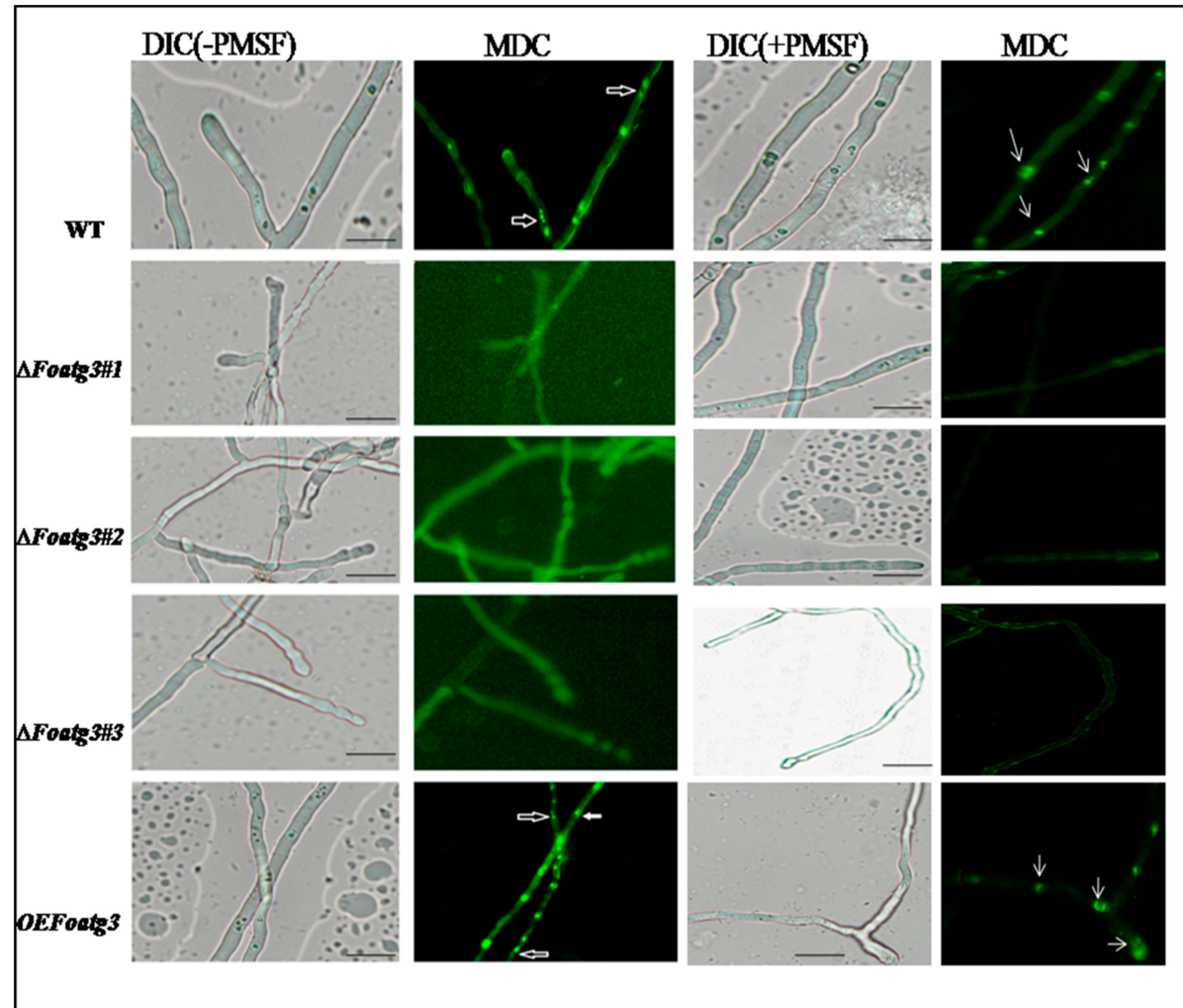

Figure 2. Representative phenotypes of atg3 WT, deletion mutant, and over expression. Foatg3 is a basic component and necessary for starvation-induced autophagy. Micro graphs showing hyphae of monodansylcadaverine (MDC) stained strains. White arrows indicating the hyphal compartment with degraded nuclei. Error Bar $=10 \mu \mathrm{m}$. DIC: Differential interference contrast, PMSF: phenylmethylsulfonyl fluoride. 


\subsection{Role of Atg3 on Conidiation and Vegetative Growth of Fusarium Oxysporum}

In several fungi, autophagy-related genes effect conidial and vegetative growth [31,32]. To determine the role of atg3 we evaluated conidial formation and vegetative growth on liquid and solid media (both in rich and minimal). The radial growth of the $\Delta$ Fooatg3 mutant was slightly reduced whereas the development of aerial mycelium was significantly reduced in the high nutrition condition as compared to the wild type and OE Foatg3 overexpressed mutant (Figure 3A,B). Meanwhile, $\triangle$ mutant showed less production of microconidia as compared to OEFoatg3 and WT (Figure 3C). Also, in liquid culture recovered microconidia from $\Delta$ Foatg 3 mutant were less then WT and over expressed mutant (Figure 3D).
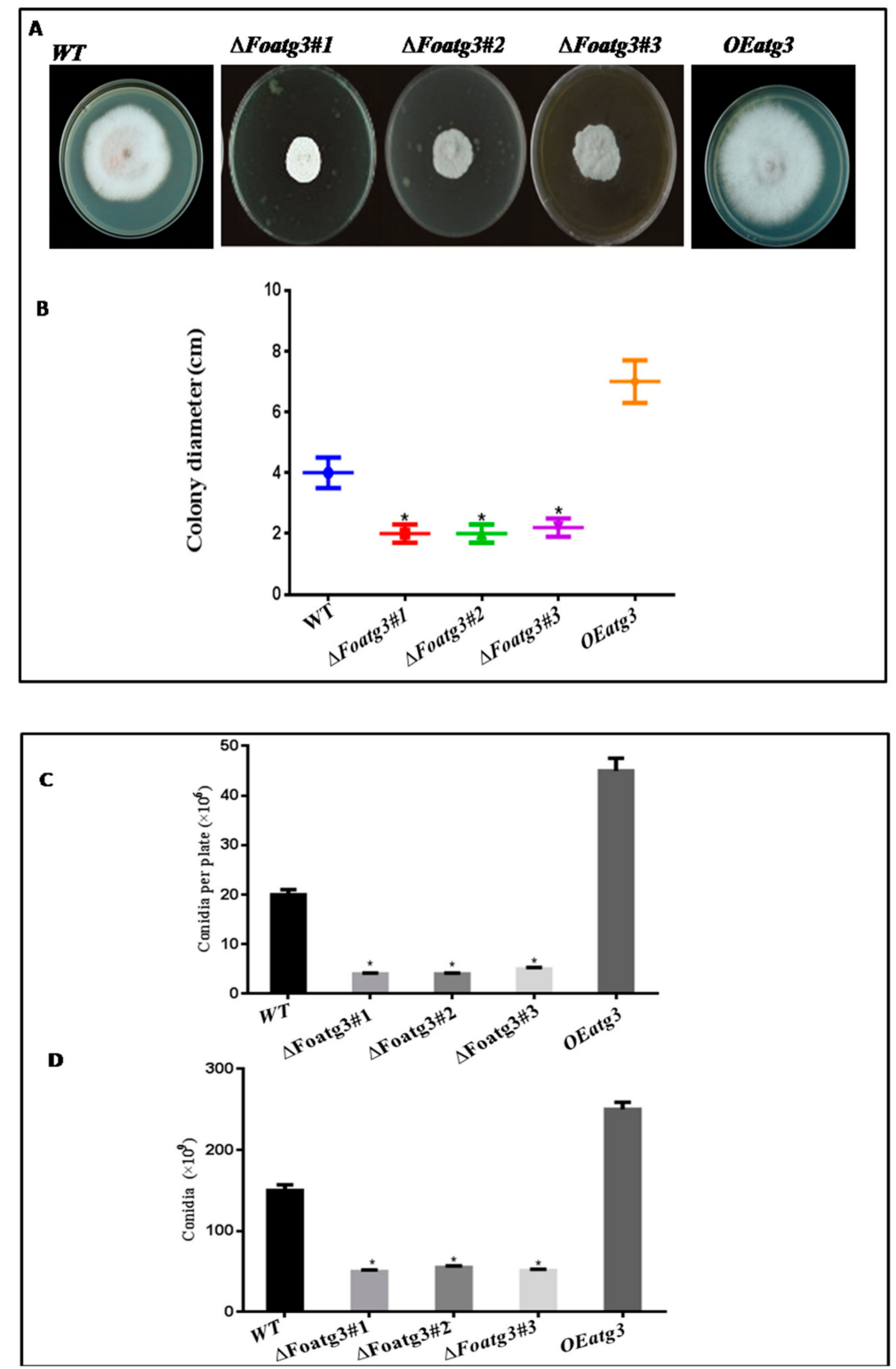

Figure 3. Conidia and hyphal formation were significantly reduced in the Foatg3 mutant. (A) Showing fungal colony after 7 days of strain inoculation. (B) Graph showing comparative growth of different fungal strains. Fresh microconidia were inoculated in PDA media and then incubated at $28{ }^{\circ} \mathrm{C}$. The diameter of the fungal colonies was measured daily for 7 days and then plotted. (C) Graph showing the number of microconidia grown on PDA medium at $28^{\circ} \mathrm{C}$ after 7 days. (D) Graph showing the number of microconidia recovered after 2 days at $28^{\circ} \mathrm{C}$. The error bars on the graph indicate the standard error. $t$-test with a $p$ value $<0.05$ was used for statistical analysis. 
Moreover, the autophagy inducing mutants grown under severely nutrient limited conditions (SM diluted 1:1000) showed retarded growth without detectable aerial hyphae and redial growth, which was probably due to the starvation condition that encounters growth (Figure S3A,B). Additionally, in nutrient limited conditions, the $\Delta$ Foatg 3 mutant reduced conidial production in both liquid and solid medium as compared to the OE Foatg3 mutant and wild type (Figure S3C,D). Hence, based on these findings it is evident that autophagy is a compulsory mechanism for vegetative growth and conidial formation in F. oxysporum.

\subsection{Role of Atg3 in Cellular Distribution of Nuclei in F. Oxysporum}

During vegetative growth of F. oxysporum, nuclei divide mitotically. Thus, we hypothesized the effect of autophagy on cellular distribution of nuclei in the hyphal compartment during epical extension. The hyphal cell walls were stained with calcofluor white (CFW) chitin binding dye in order to visualize and determine the number of nuclei per compartment of hyphae. The deletion mutant ( $\Delta$ Foatg3) contained exclusively multinucleate hyphal compartments as compared to the wild type. Mostly the hyphal compartments contained two or more nuclei in the deletion mutant (Figure 4). Moreover, the mitotic pattern in the overexpressed mutant was similar to wild type. These results suggest that during vegetative growth of F. oxysporum autophagy contributes to the control division of nuclei in the hyphal compartment.

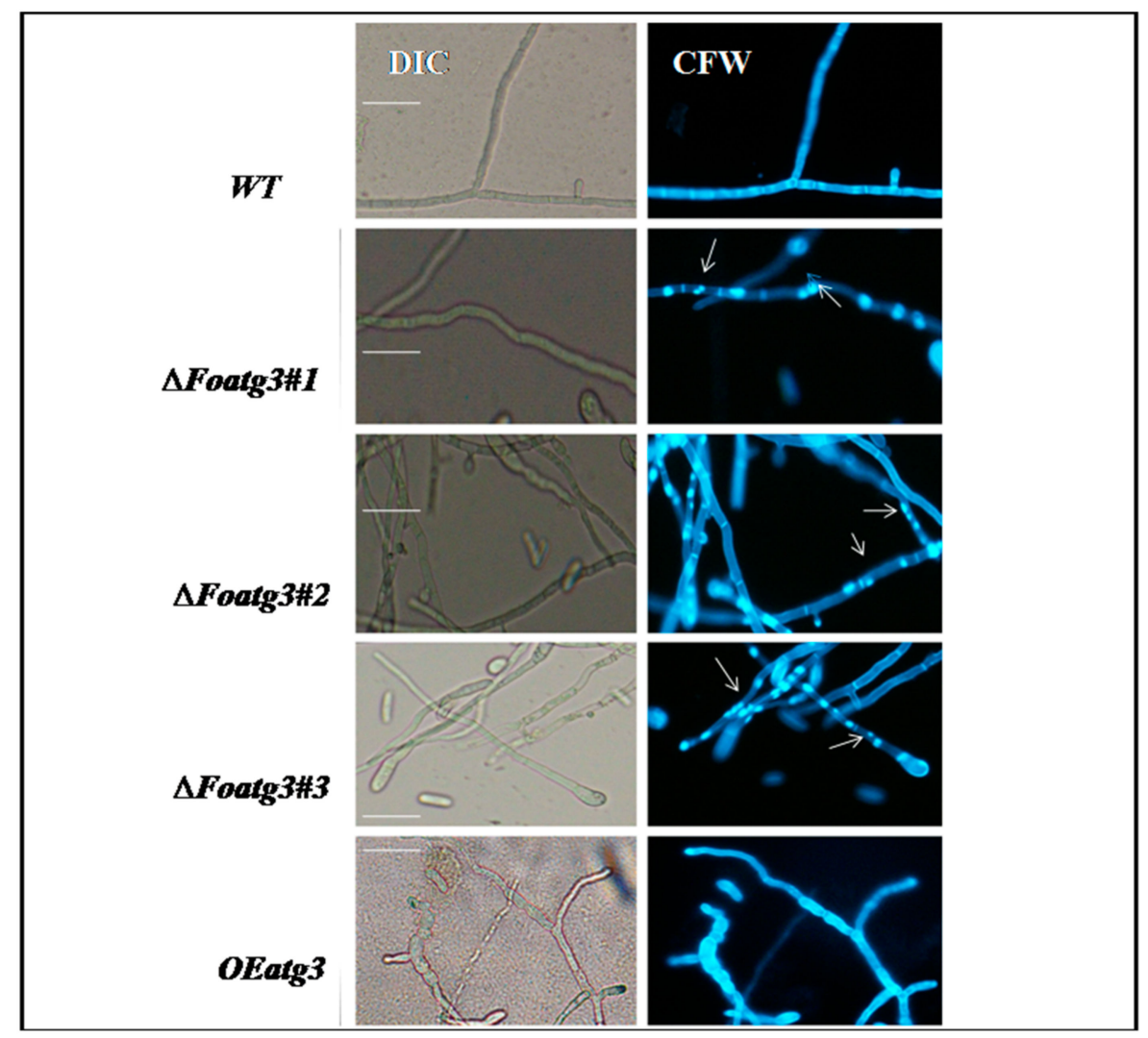

Figure 4. Hyphae from Foatg3 mutants contain multinucleated compartments. Image represents hyphae of the nitrogen starvation strains which were stained with calcofluor white (CFW). Micro arrows indicating the hyphal compartment which contains more than one nucleus. Error Bar $=10 \mu \mathrm{m}$.

\subsection{Autophagy Affects on Virulence of F. Oxysporum}

To investigate the role of autophagy on the pathogenicity of F.oxysporum, potato tubers were inoculated with an equivalent amount of WT, Foatg $3 \Delta$, and Foatg3 OE spores independently. After 7 days of inoculation, aerial mycelium of different strains were observed on infected potato tubers. 
The colonies of the Foatg $3 \Delta$ mutant completely failed in radial growth and in formation of aerial mycelium as compared to WT and OE mutants. While wild type WT and overexpressed mutants, OE Foatg3 increased radial growth and aerial mycelium on inoculated potato tubers (Figure 5A,B).

The disease cycle in the filamentous fungi initiates with conidia formation [33,34]. We keenly observed the infection process after inoculation in order to find out the reason for failed radial growth in the Foatg $3 \Delta$ mutant. The microscopy revealed all fungal strains to germinated conidia after 7 days; however, the Foatg $3 \Delta$ mutant was found to have fewer conidial spores as compared to both the WT and OE Foatg3 mutant strains (Figure S4). This observed inability of the Foatg $3 \Delta$ mutant to produce the desired conidia can be seen as an important component in the mutant's infectivity and virulence.

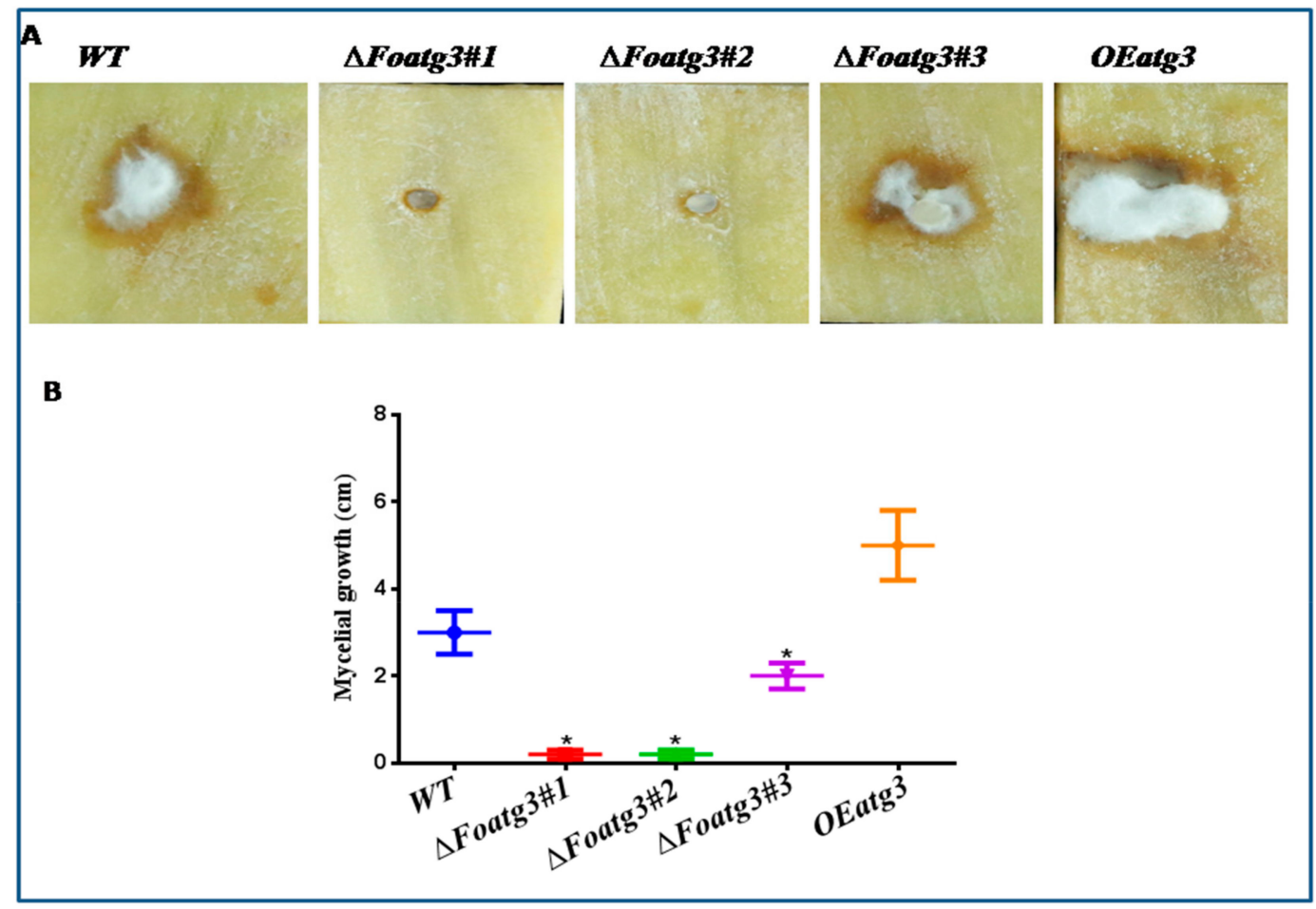

Figure 5. Foatg3 contributes to virulence on potato tuber slices. Mycelial growth was reduced in the Foatg $3 \Delta$ mutant. (A) Tubers slices were inoculated with F. oxysporum strains kept at room temperature and photographed after 7 days. These images represent strains growth after 7 days. (B) Graph represents colony formation after six days. $t$-test with a $p$ value $<0.05$ was performed for statistical analysis.

\section{Discussion}

Autophagy is recognized as a conserved cellular pathway evolved in eukaryotes to cope with different stresses stimuli. It is a vital protective strategy at the cellular level responsible for getting rid of unnecessary and toxic cytoplasmic materials, avoiding cellular damage due to different cellular stress, leading to changes in cellular mechanism during differentiation, and coming about as the result of turnover of organelles and proteins [35-37]. F. oxysporum is reported to exhibit an acropetal growth pattern during vegetative stages, which makes it a suitable candidate to be used as a mononucleated as well as compartmented organism in mycelial investigations [38]. Several findings indicate the presence of an effective and robust cellular mechanism to monitor the cell volume, control the compartmentalization and other stages of the cell cycle, thereby maintaining the uninucleate status of hyphal compartments during vegetative growth and fusion.

Here we adopted a reverse genetic approach to evaluate the role of autophagy-related gene Foatg3 in this cellular maintenance process. It has been widely reported that the F. oxysporum genome encodes most of the known ATG proteins for nonselective macroautophagy, which is similar to other filamentous ascomycetes. In F. oxysporum, the gene Foatg 8 is essential for the autophagy pathway, 
which participates in production of conidia, formation of appressoria and virulence of this fungus [39-41]. In agreement with these lines, here we found that, the Foatg3 gene is an important component for the autophagy pathway; the autophagy-related gene Foatg3 affects the growth and developmental process of filamentous fungus by affecting production of conidia and thus the virulence of F. oxysporum.

One of the key roles of autophagy is the recycling of nutrients to ensure survival of the organism in response to starvation conditions. We found nitrogen-starved autophagy in F. oxysporum, as reported previously in F. graminea [17,39]. The absence of MDC positive staining in nitrogen-starved $\triangle$ Foatg 3 mutants strongly suggests that FoAtg3 is essential for autophagy in F. oxysporum. Autophagy is responsible for the internal recycling of cytosolic materials and the cellular organelles within the cells. This property facilitates the trafficking of intra cellular in the hyphal filaments subsequently enhancing the conidiophore containing aerial hyphae [18]. In agreement with this hypothesis, $\Delta$ Foatg3 mutants showed marked reduction in the growth of conidia and aerial hyphae as compared to the overexpression mutant along with the wild type strains $[19,40,42]$. The Foatg $3 \Delta$ mutants were also undergoing aberrant mitotic events that caused a significant increase in the fraction of hyphal compartments which contained more than one nucleus, suggesting that filamentous fungi may use nuclei as nutrient pools for supporting hyphal tip growth via autophagy. In nutrient limited conditions, the success of fungal infection relies upon the recycling and availability of the crucially important macromolecules to facilitate the hyphal growth in the host cells. It has been reported that the loss of the MoATG8 gene in $M$. oryzae exponentially increases the conidial cell death by autophagy which retards appressorium arrangement ultimately leading to the loss of pathogenicity [41,43]. At par with the results in M. oryzae, the CoATG8 is also attributed to be responsible for regulating the conidiation process, pattern of appressorium arrangement, as well as the pathogenicity levels in C. orbiculare [44,45]. The disease cycles of the filamentous fungi are initiated by the germination of spores [34]. Our findings confirm that the virulence of $\Delta$ Foatg 3 mutants on potato tubers was significantly attenuated and reduced conidial production. However, reduction in conidial production can be an important factor which effects the pathogenicity of $\Delta$ Foatg3. We found that the virulence of Foatg3 mutants on potatoes was significantly reduced. The colonies of the Foatg $3 \Delta$ mutant completely failed in radial growth and also in formation of the arial mycelium as compared to wild type and overexpressed mutants after 7 days of inoculation. The Foatg $3 \Delta$ mutant also produced less spores as compared to wild type and overexpression. This inability of Foatg $3 \Delta$ to produce expected conidial spores is found to be the main factor responsible for its decreased infectivity. In conclusion, the present study revealed that autophagy controls formation of spores and also effects the virulence of $F$. oxysporum, which could be used for the future plant fungal disease control strategy. These results provide insights into the role of autophagy in regulation of vegetative growth and development of F. oxysporum. However, further studies are required to elucidate the role of atg 3 in other fungal strains and investigate the detailed functions of Foatg3 in vegetative growth and formation of autophagosomes.

Supplementary Materials: The following are available online at http://www.mdpi.com/2073-4425/10/9/658/s1, Figure S1: Image represents map of vectors (A) The Foatg3 coding region was replaced with the HygB cassette. (B) Construction of the GFP Foatg3 fusion protein. The Foatg3 cDNA fragment was amplified with the indicated primers containing Sbf1 and Asc1 restriction sites inserted at 5' and 3' end respectively, Figure S2: Image represent expected shift in deletion mutant and over expression of mutants, Figure S3: In nutrient lacking media hyphal formation was very faint. (A) Represents the image of 7 days old strains after inoculation. (B) After 7 days number of micro conidia recovered from PDA plates which were grown on $28^{\circ} \mathrm{C}$. (C) Represents the number of recovered micro conidia from 2 days old culture with shaking at $28^{\circ} \mathrm{C}$. Bars indicating slandered error from replications. To perform statistical analysis $t$-test was used. ${ }^{*} p<0.05$, Figure S4: After seven days of inoculation all strains produced micro conidia. In Foatg $3 \Delta$ mutant conidial production was suppressed compared to wild type (WT) and overexpression (OE). Image represents conidial germination in different strains, Table S1: Primers used for construction of replacement cassette and genes cloning in this study.

Author Contributions: Data curation, X.L.; Formal analysis, M.N., K.M. and H.S.; Funding acquisition, P.D. and D.Q.; Supervision, M.R.; Writing-original draft, A.R.K. 
Funding: This work was supported by the National Key R\&D Program of China: 2018YFD0200808 and 2016YFD0100306, National Natural Science Foundation of China: No. 31672206 and 31801911, Chongqing Frontier and Applied Basic Research: No. 31672206 and 31801911, Chongqing Frontier and Applied Basic Research: No. 2018CDGFSM0021 and 106112017CDJQJ29883.

Acknowledgments: Current research work was financially supported by Chongqing Frontier and Applied Basic Research (No. cstc2018jcyjAX0753 and cstc2015shms-ztzx0121); National Key R\&D Program of China (2018YFD0200808 and 2016YFD0100306); the National Natural Science Foundation of China (No. 31672206 31972469 and 31672206). The support of the Fundamental Research Funds for the Central Universities (No. 2018CDGFSM0021 and 106112017CDJQJ29883) are also acknowledged.

Conflicts of Interest: The authors declare no conflicts of interest.

\section{Abbreviations}

$\begin{array}{ll}\text { ATG } & \text { Autophagy-related gene } \\ \text { WT } & \text { Wild type } \\ \text { OE } & \text { Overexpression } \\ \Delta & \text { Deletion mutant } \\ \text { MDC } & \text { Monodansylcadaverine } \\ \text { DIC } & \text { Differential interference contrast }\end{array}$

\section{References}

1. El-Kassas, H.Y.; Khairy, H.M. A trial for biological control of a pathogenic fungus (Fusarium solani) by some marine microorganisms. Am. Eurasian J. Agric. Environ. Sci. 2009, 5, 434-440.

2. Wharton, P.K.W. Fusarium Dry Rot. 2007. Available online: http://www.Potatodiseases.Org/contact.html (accessed on 23 May 2007).

3. Chełkowski, J. Toxinogenicity of Fusarium Species Causing Dry Rot of Potato Tubers; Elsevier, B.V.: New York, NY, USA, 1989; Chapter 25; pp. 435-440.

4. Slininger, P.J.; Burkhead, K.D.; Schisler, D.A. Antifungal and sprout regulatory bioactivities of phenylacetic acid, indole-3 acetic acid, and tyrosol isolated from the potato dry rot suppressive bacterium Enterobacter cloacae S11:T:07. J. Ind. Microbiol. Biotechnol. 2004, 31, 517-524. [CrossRef] [PubMed]

5. Secor, G.A.; Gudmestad, N.C. Managing fungal diseases of potato. Can. J. Plant Pathol. 1999, $21,213-221$. [CrossRef]

6. Shattock, R. Compendium of Potato Diseases, Second Edition. Plant Pathol. 2002, 51, 520. [CrossRef]

7. Saccardo, P.A. Sylloge Fungorum Omnium Hucusque Cognitorum; Edwards Brothers Malloy: Ann Arbor, MI, USA, 1882.

8. Secor, G.A.; Salas, B. Fusarium dry rot and fusarium wilt. In Compendium of Potato Diseases; Stevenson, W.R., Loria, F., Franc, G.D., Weingartner, D.P., Eds.; APS Press: St. Paul, MN, USA, 2001; pp. 23-25.

9. Yangui, T.; Sayadi, S.; Dhouib, A. Sensitivity of pectobacterium carotovorum to hydroxytyrosol-rich extracts and their effect on the development of soft rot in potato tubers during storage. Crop Prot. 2013, 53, 52-57. [CrossRef]

10. Boya, P.; Reggiori, F.; Codogno, P. Emerging regulation and functions of autophagy. BMC Cell Biol. 2013, 15, 713-720. [CrossRef] [PubMed]

11. Thompson, A.R.; Vierstra, R.D. Autophagic recycling: Lessons from yeast help define the process in plants. Curr. Opin. Plant Biol. 2005, 8, 165-173. [CrossRef] [PubMed]

12. Wang, Y.; Cai, S.Y.; Yin, L.L.; Shi, K. Tomato HsfA1a plays a critical role in plant drought tolerance by activating ATG genes and inducing autophagy. Autophagy 2015, 11, 2033-2047. [CrossRef] [PubMed]

13. Zhou, J.; Yu, J.Q.; Chen, Z.X. The perplexing role of autophagy in plant innate immune responses. Mol. Plant Pathol. 2014, 15, 637-645. [CrossRef] [PubMed]

14. Zhou, X.M.; Zhao, P.; Wang, W.; Zou, J. A comprehensive, genome-wide analysis of autophagy-related genes identified in tobacco suggests a central role of autophagy in plant response to various environmental cues. DNA Res. 2015, 22, 245-257. [CrossRef]

15. Bartoszewska, M.; Kiel, J.A. The role of macroautophagy in development of filamentous fungi. Antioxid. Redox Signal. 2011, 14, 2271-2287. [CrossRef] [PubMed] 
16. Khan, I.A.; Lu, J.P.; Liu, X.H.; Rehman, A. Multifunction of autophagy-related genes in filamentous fungi. Microbiol. Res. 2012, 167, 339-345. [CrossRef] [PubMed]

17. Zhai, Y.F.; Guo, M.; Wang, H.; Lu, J.P.; Liu, J.; Zhang, C.; Gong, Z.; Lu, M. Autophagy, a conserved mechanism for protein degradation, responds to Heat, and other abiotic stresses in Capsicum annuum L. Front. Plant Sci. 2016, 7, 131. [CrossRef] [PubMed]

18. Chung, T.; Suttangkakul, A.; Vierstra, R.D. The ATG autophagic conjugation system in maize: ATG transcripts and abundance of the ATG8-Lipid adduct are regulated by development and nutrient availability. Plant Physiol. 2009, 149, 220-234. [CrossRef] [PubMed]

19. Kwon, S.I.; Cho, H.J.; Kim, S.R.; Park, O.K. The rab GTPase rabG3b positively regulates autophagy and immunity-associated hypersensitive cell death in arabidopsis. Plant Physiol. 2013, 161, 1722-1736. [CrossRef] [PubMed]

20. Maruthachalam, K.; Klosterman, S.J.; Kang, S.; Hayes, R.J. Identification of pathogenicity related genes in the Vascular Wilt Fungus Verticillium dahliae by agrobacterium tumefaciens-mediated T-DNA Insertional mutagenesis. Mol. Biotechnol. 2011, 49, 209-221. [CrossRef] [PubMed]

21. Liu, Y.G.; Chen, Y. High-efficiency thermal asymmetric interlaced PCR for amplification of unknown flanking sequences. BioTechniques 2007, 43, 649-650. [CrossRef] [PubMed]

22. Klosterman, S.J.; Subbarao, K.V.; Kang, S.C.; Veronese, P. Comparative genomics yields insights into niche adaptation of plant vascular wilt pathogens. PLoS Pathog. 2011, 7, e1002137. [CrossRef] [PubMed]

23. Szewczyk, E.; Nayak, T.; Oakley, C.E.; Edgerton, H.; Xiong, Y.; Taheri-Talesh, N.; Osmani, S.A.; Oakley, B.R. Fusion PCR and gene targeting in Aspergillus nidulans. Nat. Prot. 2006, 1, 3111-3120. [CrossRef]

24. Di Pietro, A.; Roncero, M.I.G. Cloning, expression, and role in pathogenicity of pg1 encoding the major extracellular endopolygalacturonase of the vascular wilt pathogen Fusarium oxysporum. Mol. Plant Microbe Interact. 1998, 11, 91-98. [CrossRef]

25. Klionsky, D.J.; Abdalla, F.C.; Abeliovich, H.; Abraham, R.T.; Acevedo-Arozena, A.; Adeli, K.; Agholme, L.; Agnello, M.; Agostinis, P.; Aguirre-Ghiso, J.A.; et al. Guidelines for the use and interpretation of assays for monitoring autophagy. Autophagy 2012, 8, 445-544. [CrossRef] [PubMed]

26. Biederbick, A.; Kern, H.F.; Elsasser, H.P. Monodansylcadaverine (Mdc) is a specific in-vivo marker for autophagic vacuoles. Eur. J. Cell Biol. 1995, 66, 3-14. [PubMed]

27. Josefsen, L.; Droce, A.; Sondergaard, T.E.; Sorensen, J.L. Autophagy provides nutrients for nonassimilating fungal structures and is necessary for plant colonization but not for infection in the necrotrophic plant pathogen Fusarium graminearum. Autophagy 2012, 8, 326-337. [CrossRef] [PubMed]

28. Husaini, A.M.; Sakina, A.; Cambay, S.R. Host-pathogen interaction in Fusarium oxysporum infections: Where do we stand? Mol. Plant Microbe Interact. 2018, 31, 889-898. [CrossRef] [PubMed]

29. De Sain, M.; Rep, M. The role of pathogen secreted proteins in fungal vascular wilt diseases. Int. J. Mol. Sci. 2015, 16, 23970-23993. [CrossRef]

30. Kazan, K.; Gardiner, D.M.; Manners, J.M. On the trail of a cereal killer: Recent advances in Fusarium graminearum pathogenomics and host resistance. Mol. Plant Pathol. 2012, 13, 399-413. [CrossRef]

31. Gordon, T.R. Fusarium oxysporum and the fusarium wilt syndrome. Annu. Rev. Phytopathol. 2017, 55, $23-39$. [CrossRef]

32. Ma, L.J.; Geiser, D.M.; Proctor, R.H.; Rooney, A.P. Fusarium pathogenomics. Annu. Rev. Microbiol. 2013, 67, 399-416. [CrossRef]

33. Levine, B.; Klionsky, D.J. Development by self-digestion: Molecular mechanisms and biological functions of autophagy. Dev. Cell 2004, 6, 463-477. [CrossRef]

34. Zhang, S.; Liu, S.; Zhang, J.; Russel, R.J.; Wang, Y.; Qiu, D.; Luo, X.; Khalid, A.R.; Wang, H.; Feng, L.; et al. Synergistic anti-oomycetes effect of melatonin with a biofungicides against oomycetic black shank diseses. J. Pineal Res. 2018, 65, e12492. [CrossRef]

35. Klionsky, D.J. The molecular machinery of autophagy: Unanswered questions. J. Cell Sci. 2005, 118, 7-18. [CrossRef] [PubMed]

36. Ruiz-Roldan, M.C.; Kohli, M.; Roncero, M.I.G.; Philippsen, P. Nuclear dynamics during germination, conidiation, and hyphal fusion of Fusarium oxysporum. Eukaryot. Cell 2010, 9, 1216-1224. [CrossRef] [PubMed] 
37. Corral-Ramos, C.; Roca, M.G.; Di Pietro, A.; Roncero, M.I.G. Autophagy contributes to regulation of nuclear dynamics during vegetative growth and hyphal fusion in Fusarium oxysporum. Autophagy 2015, 11, 131-144. [CrossRef] [PubMed]

38. Hanaoka, H.; Noda, T.; Shirano, Y.; Kato, T. Leaf senescence and starvation-induced chlorosis are accelerated by the disruption of an Arabidopsis autophagy gene. Plant Physiol. 2002, 129, 1181-1193. [CrossRef] [PubMed]

39. Xia, K.F.; Liu, T.; Ouyang, J.; Wang, R. Genome-wide identification, classification, and expression analysis of autophagy associated gene homologues in rice (Oryza sativa L.). DNA Res. 2011, 15, 363-377. [CrossRef] [PubMed]

40. Xie, Z.P.; Nair, U.; Klionsky, D.J. Atg8 controls phagophore expansion during autophagosome formation. Mol. Biol. Cell 2008, 19, 3290-3298. [CrossRef] [PubMed]

41. Richie, D.L.; Fuller, K.K.; Fortwendel, J.; Miley, M.D.; McCarthy, J.W.; Feldmesser, M.; Rhodes, J.C.; Askew, D.S. Unexpected link between metal ion deficiency and autophagy in Aspergillus fumigatus. Eukaryot. Cell 2007, 6, 2437-2447. [CrossRef]

42. Shoji, J.Y.; Kikuma, T.; Arioka, M.; Kitamoto, K. Macroautophagy mediated degradation of whole nuclei in the filamentous fungus aspergillus oryzae. PLoS ONE 2010, 5, 220-234. [CrossRef]

43. Nitsche, B.M.; Burggraaf-van Welzen, A.M.; Lamers, G.; Meyer, V. Autophagy promotes survival in aging submerged cultures of the filamentous fungus Aspergillus niger. Appl. Microbiol. Biotechnol. 2013, 97, 8205-8218. [CrossRef]

44. Veneault-Fourrey, C.; Barooah, M.; Egan, M.; Wakley, G.; Talbot, N.J. Autophagic fungal cell death is necessary for infection by the rice blast fungus. Science 2006, 312, 580-583. [CrossRef]

45. Khalid, A.R.; Zhang, S.; Luo, X.; Mehmood, K.; Rahim, J.; Shaheen, H.; Dong, P.; Qiu, D.; Ren, M. Role of autophagy-related gene atg22 in developmental process and virulence of Fusarium oxysporum. Genes 2019, 10, 365. [CrossRef] [PubMed]

(C) 2019 by the authors. Licensee MDPI, Basel, Switzerland. This article is an open access article distributed under the terms and conditions of the Creative Commons Attribution (CC BY) license (http://creativecommons.org/licenses/by/4.0/). 